\title{
De la multiterritorialidad a los nuevos muros: paradojas contemporáneas de la desterritorialización ${ }^{1}$
}

\author{
ROGÉRIO HAESBAERT ${ }^{2}$ \\ Universidad Federal Fluminense, Niterói, Rio de Janeiro, Brasil.
}

El espacio está en la agenda. Muchos, a partir la década de 1990, hablan de un "giro» o "vuelta» espacial. La más célebre referencia a este cambio fue Michel Foucault, siempre citado cuando se comenta el cambio de la "era del tiempo", o de la historia, referida al pasaje del siglo XIX al XX y la gradual asunción de la «era espacial», que él ya identificaba a finales de 1960 (Foucault, 200I [original escrito en 1967]). Entramos en esta "era espacial» tanto en el sentido de la exploración de los microespacios (de los genes a las micropartículas) como de los macroespacios (la exploración de la Luna o el big bang). Sin embargo, lo que nos concierne más de cerca, en cuanto geógrafos, es precisamente el énfasis actual en la espacialidad en una escala más específicamente "humana», la de nuestra reproducción y nuestra circulación como seres vivientes, móviles, que necesitan refugio, alimentos y que en todo momento, recrean el mundo para la propia resignificación y simbolización de su espacio-tiempo.

«Espacio-tiempo»: ésta es la expresión que realmente nos interesa. Mucho más que un "giro espacial», ingresamos, desde Einstein, en la era del «espacio-tiempo», de la insociabilidad entre esas dimensiones de lo social. No podemos más referirnos a esas categorías mediante genéricas dicotomías como aquellas que separan el presente del pasado, sincrónico de diacrónico, fluidez de fijación, transformación de permanencia. El

1 Ésta es la traducción de la videoconferencia titulada: «Da multiterritorialidade aos novos muros: paradoxos da des-territorialização contemporânea", realizada en el marco del III Congreso de Geografía de Universidades Públicas Argentinas, realizado en la Facultad de Humanidades y Ciencias de la Universidad Nacional del Litoral, Santa Fe, Argentina, octubre de 2011. La traducción del texto original del portugués estuvo a cargo de Lucas Gabriel Cardozo (Universidad Nacional del Litoral) y fue revisada por el autor.

2 Geógrafo, profesor de la Universidad Federal Fluminense (Niterói, Rio de Janeiro, Brasil). Doctor en Geografía Humana por la Universidad de São Paulo, con postdoctorado en la Open University (Milton Keynes, Inglaterra). 
presente geográfico puede ser visto, siempre, como la condensación de múltiples duraciones de un pasado que se contrae y, al mismo tiempo, como una apertura para un futuro de múltiples caminos y, así, de múltiples posibilidades. Por más que un espacio parezca ser una esfera de fijación y de estabilidad, en verdad él es la condición para que el tiempo futuro sea abierto y pueda realizar diferentes alternativas, colocadas a partir de esta múltiple combinación de trayectorias que incorporamos a nuestro presente, en la coetaneidad de nuestra geografía (Massey, 2008).

Multiplicidad es una palabra de moda, una marca, para muchos, de nuestros tiempos "posmodernos» o "posestructuralistas». Pero tenemos que tener mucho cuidado con ella. Sobrevalorarla puede llevarnos a esconder, muchas veces, la difícil tarea de encontrar nuevos caminos dentro de un espacio formado por sujetos poderosos que dictan la mayoría de las reglas/normas a través de una sociedad gobernada, principalmente, por la lógica contable de la economía de mercado, donde casi todo, hoy, es pasible de compra y venta. Pero también no podemos, por otro lado, ignorar las múltiples trayectorias que el espacio nos pone para estimularmos la creación de nuevos o, en palabras de Deleuze y Guattari (1995), los momentos efectivos de «desterritorialización» en que las "líneas de fuga» nos llevan a la construcción de nuevos agenciamientos, tanto en el campo de las prácticas y de las representaciones del espaciales.

«Desterritorialización» también llegó a ser un término de moda desde la década de 1990, a pesar de que Deleuze y Guattari ya lo proponían, por lo menos, desde la década de 1970. ${ }^{1}$ Todo parecía desarraigarse, perder cualquier base sólida o, al menos, hibridarse. Las bases territoriales de control más conocidas, aquellas relativas al Estado, parecían cada vez más debilitadas. El mismo capitalismo tendía a «flexibilizarse», perdiendo la rigidez de su etapa fordista, y la expresión famosa de Marx, "todo lo sólido se desvanece en el aire», popularizada por Marshall Berman (1986), parecía tener realmente sentido. Pero ese desvanecimiento y esa desechabilidad socioespacial, en su mayor parte, tenían la dirección correcta: realimentar el espiral del crecimiento y de la especulación que, resultaría en crisis regionales o mundiales que, en mayor o menor grado, terminarían afectándonos a todos. Y no se trataba sola-

1 Sobre esta temática, ver nuestro abordaje en Haesbaert (2011 [original en portugués, 2004]), sobre todo en el capítulo 3. 
mente de crisis económicas, sino que también abarcaban el campo de los valores, crisis de representación en la manera de ver el mundo y su espacio (véase, por ejemplo, lo que pasó después de la caída de las torres gemelas en Nueva York 200I, y la ambigüedad simbólica adquirida por el II de septiembre).

En la actualidad, la inestabilidad y la incertidumbre, sin duda, inundan nuestras geografías, desde el espacio local, más cotidiano, hasta el global. Ni siquiera la dimensión material de nuestros espacios, empezando por los rápidos cambios derivados del cambio climático, permiten imaginarnos el espacio como una dimensión de permanencia y de «larga duración» — como defendiera el historiador Fernand Braudel-.$^{2}$ En lugar de ello, ahora, de una desterritorialización como la destrucción inexorable de nuestros territorios, visto como espacios efectivamente dominados y/o apropiados, lo que encontramos es un cambio mucho más rápido del territorio, configurando lo que propusimos denominar «multiterritorialidad»: la experiencia/vivencia, concomitante o sucesiva, de múltiples territorios en la composición de nuestra territorialidad.

Si los territorios son espacios de ejercicio del poder, de relaciones de poder hechas (en/por el) espacio, sin embargo, este poder tiene muchas caras. Debemos considerar desde el poder político "tradicional», restringido a la figura del Estado y/o al poder de las «clases hegemónicas», hasta el poder en sentido más amplio, que también enfatiza su dimensión simbólica (véase, por ejemplo, el «poder simbólico» como lo define Bourdieu, 1989).

Para nuestro tratamiento del poder y, en parte, del territorio, tomaremos como referencia central a Michel Foucault. Para él, en una visión más amplia del poder, toda relación social es también una relación de poder, el poder no sólo represivo sino también "productivo». La cuestión fundamental que se plantea no es la que responde a «lo que es» el poder, sino el «cómo se ejerce.» Por lo tanto, también, la relevancia de formas espaciales/territoriales en las cuales el poder es producido.

2 Solamente en la primera fase de su obra, subráyese, sobre todo en la Introducción de «El Mediterráneo y el Mundo Mediterránico en la época de Felipe Il» (Braudel, 1983), cuando él, de manera polémica, caracteriza el tempo histórico de larga duración como «tiempo geográfico» (enfatizando, es cierto, una geografía física en la que la naturaleza sería aún considerada, sobre todo, por sus ritmos lentos). 
Para Foucault (2008), a lo largo del mundo moderno se superponen tres formas básicas del poder: (i) el (macro)poder soberano, forjado principalmente por el Estado, en el ejercicio de la soberanía, es decir, el control sobre su territorio de jurisdicción; (ii) el poder disciplinar, con toda una "microfísica» que produce la disciplina a partir de la estandarización del tiempo y el espacio a nivel individual, y (iii) el biopoder o poder sobre la vida, que se realiza a través del hombre visto como una "población» en su «medio» de movimiento y de la reproducción como ser viviente, biológico.

Foucault, infelizmente, vinculó a su amplia visión del poder un enfoque muy restringido de territorio, pues se restringió el uso del término a la espacialidad del poder estatal, el poder soberano. En Geografía, desde hace mucho tiempo (por lo menos desde Jean Gottman en la década de 1950), se superó el enfoque que combina el territorio sólo a la figura del Estado, como, de alguna manera, se había propuesto el geógrafo alemán Friedrich Ratzel, al final del siglo XIX. Hoy en día, el territorio se puede ver en diversas escalas (Souza, 1995) y a través de una concepción mucho más amplia de poder (Haesbaert, 2004) e incluye incluso la apropiación simbólica de espacios que, de esta manera, para los grupos que se identificarse con ellos, conduce a una suerte de empoderamiento. En este sentido, podemos decir que, al menos desde Antonio Gramsci, ya se lograba hacer la conexión entre poder político como coerción en su sentido estatal (y/o representativo de una clase), y poder simbólico o de consentimiento, en el sentido gramsciano de construcción de la hegemonía.

Por lo tanto, podemos afirmar que las territorialidades dominantes en el mundo moderno de matriz europea impusieran inicialmente una estandarización territorial, de carácter supuestamente universal y exclusiva, cuya matriz era el Estado y sus dominios en área, construyendo «territorios-zona» que no admitían la superposición y cuya multiterritorialidad tenía un carácter meramente funcional, dentro de una lógica de control piramidal: al territorio «mínimo» de la propiedad privada se superponía al territorio municipal que, a su vez, estaría dentro de territorios «departamentales» o "provinciales», y luego incorporados en el territorio estatal como un todo y, más recientemente, por lo menos en el caso de la Unión Europea, una entidad de bloque supranacional o internacional de poder.

$\mathrm{Al}$ mismo tiempo, no podemos olvidar que, en general, bajo el beneplácito del Estado, se superpone de modo cada vez más intrincado una 
u otra forma de organización territorial, los «territorios-redes» de las grandes corporaciones empresariales, en un proceso gradual de multi o transnacionalización. A diferencia del poder estatal, todavía, especialmente con el fin del dominio colonial, las empresas se interesan más por un control de los flujos y redes que de áreas o zonas - estas, todavía representan la parcela inseparable que las «vincula» a sus territoriosredes. La lógica territorial de las grandes corporaciones es siempre, en cierto sentido, multi (o incluso "trans») territorial, en la medida que se estructura su poder mediante la organización de una inmensa articulación de territorios, desde los territorios-zona en que construyen la infraestructura de sus bases productivas y/o de circulación hasta la conexión en red alrededor del mundo, realizando de este modo inmensos circuitos de flujos sobre los cuales ejercen efectivamente su control.

Se trata, también, de una multiterritorialidad dentro de una misma lógica funcional, globalmente estandarizada. La diferencia en relación a la multiterritorialidad funcional del Estado y de las grandes empresas es que, en cuanto la del Estado se hace por encaje simultáneo de territorios-zona autocontenidos, la de las grandes empresas se realiza por la sucesión de territorios-zona articulados, formando grandes territoriosred donde el control más importante no ocurre sobre áreas/zonas/superficies pero sobre ductos y/o flujos y puntos de conexión o bubs que, combinados, forman las redes transnacionales.

Hoy, junto al «sujeto» de la gran empresa capitalista, aparecen también los propios grupos culturales, en sus migraciones diaspóricas de carácter global, construyendo y vivenciando una multiterritorialidad compleja alrededor del mundo. Esta, a diferencia de la multiterritorialidad también en red, meramente funcional, de las empresas globales, se refiere a una mayor multiplicidad de dimensiones del poder. El migrante en diáspora, a través de las múltiples territorialidades a las que pertenece, tiene «trucos» («trucos espaciales», según el geógrafo Ma Mung, 1999) para utilizar cuando sea necesario, en la medida en que, en general, puede accionar conexiones situadas en diferentes contextos territoriales (locales, nacionales) en todo el mundo.

Este migrante globalizado puede estar vinculado a territorialidades locales (un barrio de una gran metrópolis), regionales (una región y una lengua o dialecto del país de origen o de destino), nacionales (el Estado-nación en el que se sitúa y/o de donde partió) y globales (el propio territorio-red de la diáspora a la que pertenece). La multite- 
rritorialidad que él construyó por el accionar — simultáneo y/o sucesivo- de las múltiples territorialidades está compuesto no sólo por la «funcionalidad» que lo conduce, por ejemplo, a establecer una red de ayuda financiera transnacional, sino también por la identificación que él crea con una gran multiplicidad de territorios, permitiendo, incluso, si un grupo más abierto, la construcción de territorialidades híbridas con otras etnias y/o nacionalidades. Eso de modo muy distinto a la multiterritorialidad simplemente funcional de los grandes ejecutivos de empresas multinacionales que, por más que frecuenten diferentes territorios alrededor del mundo, acaban recreando siempre sus «burbujas» de seguridad, en convivencia entre iguales, que les impide dialogar con territorialidades efectivamente distintas.

Estos migrantes en diáspora pueden, al mismo tiempo, ser el núcleo de múltiples territorialidades, abiertas, en constante reconstrucción por el tránsito por distintos territorios «ajenos», y ser objeto también, a formas de reclusión o confinamiento, como ocurre cuando se forman guetos - sean "guetos voluntarios» cuando sólo se encuentran entre sus semejantes (reproduciendo rasgos de algunos grupos hegemónicos) o "guetos efectivos», cuando en cuanto grupos subalternos, son obligados a cerrarse en espacios más precarios en el interior de las ciudades.

Es justamente frente a esa precarización social o, en otras palabras, la desterritorialización en sentido más estricto, esto es, la relativa pérdida de control de sus territorios, que estos grupos subalternos son objetos de medidas, a veces de reclusión, como en el poder disciplinar que propone retirar por un tiempo a los «anormales» de la convivencia social con el supuesto de "rescatarlos» más adelante (una "reclusión por secuestro» como alude Foucault, 200I), a veces de contención — como denominamos a los actuales procesos biopolíticos de control de la circulación, especialmente en relación con los flujos migratorios globales.

Entendemos que la actual proliferación de nuevos muros a lo largo de las fronteras internacionales (ver el Mapa I) refleja, sobre todo, las biopolíticas contención de la circulación -especialmente el movimiento de los llamados circuitos ilegales, sea de personas (migrantes), el contrabando de mercancías, el tráfico de drogas, etc.- - Foucault, en este sentido, también nos ayuda a comprender este fenómeno, en particular al proponer que la principal marca espacial de las sociedades biopolíticas —o de control, como prefiere Deleuze (o, como preferimos, 
de «in-seguridad») - es el "medio» en tanto espacio donde se lleva a cabo la circulación, sea de flujos naturales (como el agua y el viento), sea de flujos sociales (como la movilidad de personas). Como se ha afirmado, la biopolítica tiene como preocupación primera el gobierno de la «población» en su circulación y/o reproducción biológica, uniéndose a la institucionalización de saberes como los de la Estadística — «ciencia del Estado"- capaz de proporcionar los datos indispensables a la gestión económica y al control del comportamiento general del hombre visto como especie, es decir, como «población».

Fuente: R. Haesbaert, 2010.
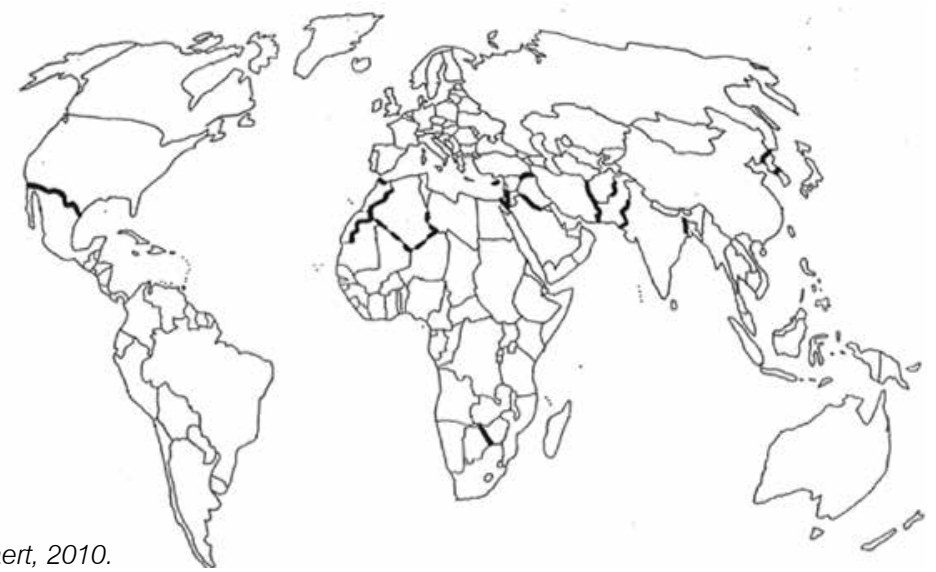

Mapa 1: Los principales muros y cercas fronterizas en el mundo contemporáneo.

En un mundo como el nuestro, por un lado marcado por la fluidez del espacio, las cuestiones ligadas a la circulación son aún más relevantes y, con ellas, la situación de uno de los componentes más emblemáticos de los territorios: sus fronteras o, en la lectura más simple, sus límites. Y es ahí que surge una de las grandes paradojas de la geografía contemporánea: al lado de la fluidez globalizada de las redes y de la «desterritorialización» (y/o multiterritorialidad) también aparecen los cerramientos, los intentos de controlar los flujos, la circulación, especialmente la circulación de personas, de la fuerza de trabajo, de los migrantes.

Este control de la circulación puede ser producido por una especie de confinamiento de redes (por la producción de circuitos aislados), por la 
forma de represa $\mathrm{a}^{3}$, como preferimos, de contención territorial, con la construcción de «diques»y, finalmente, puede ocurrir a través de (con) ductos, un efecto de canalización de estos flujos. En este sentido, una de las estrategias aparentemente más anacrónica, hoy en día, es la construcción de nuevos muros, desde el nivel de la propiedad privada, los condominios cerrados (gated communities, en la realidad norteamericana, countries en Argentina) y los barrios (como en los barrios romaníes o de inmigrantes en Europa) hasta los muros fronterizos, como el famoso muro de la frontera entre Israel y Palestina, o entre México y Estados Unidos. En el caso brasilero tenemos los «muros-presas» construidos para detener la expansión de los barrios marginales de Rio de Janeiro y Sáo Paulo (Figuras I y 2), y los muros-(con) ductos a lo largo de las carreteras con amplia circulación, para evitar el contacto (incluso visual) con las poblaciones más pobres (el caso de Linha Vermelha en Rio de Janeiro, ver Figura 3).

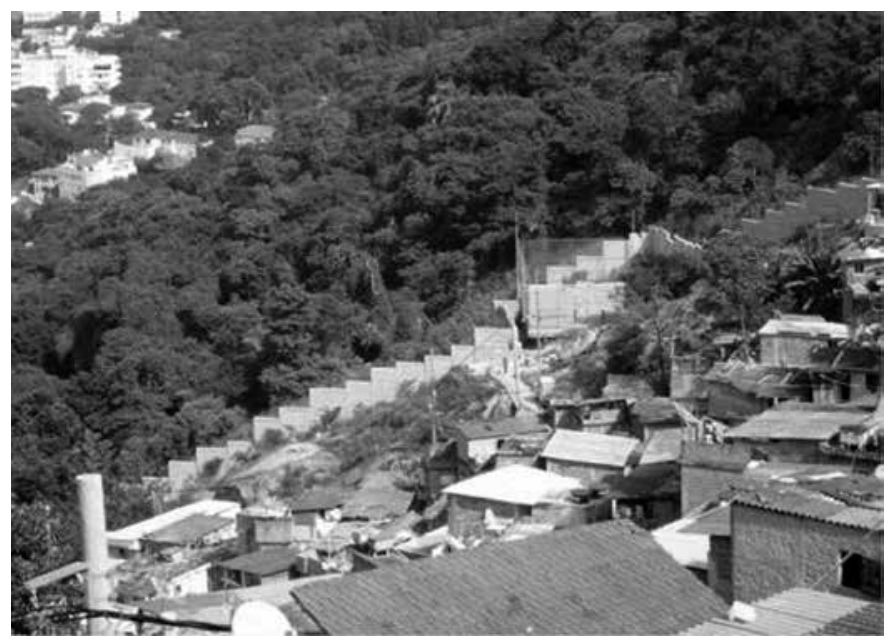

Fuente: Haesbaert, 2010.

Figura 1: Muro-barrera de contención de la expansión de la favela Santa Marta, en Rio de Janeiro, conocido retóricamente como ecolímite.

3 Nota del traductor: barragem en portugués. 
Fuente: Haesbaert, 2009.

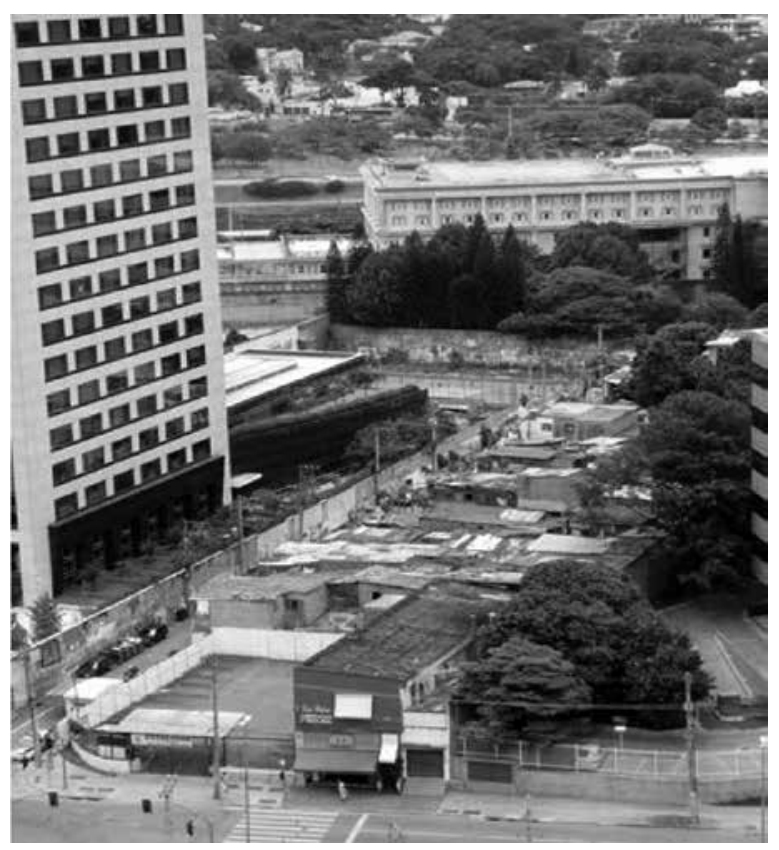

Figura 2: Parte remanente de una favela «intra-muros» junto a Daslu, una de las más lujosas y estilizadas de São Paulo (al fondo), y la «E-Tower», un centro de negocios (a la izquierda).

Fuente: Haesbaert, 2010.

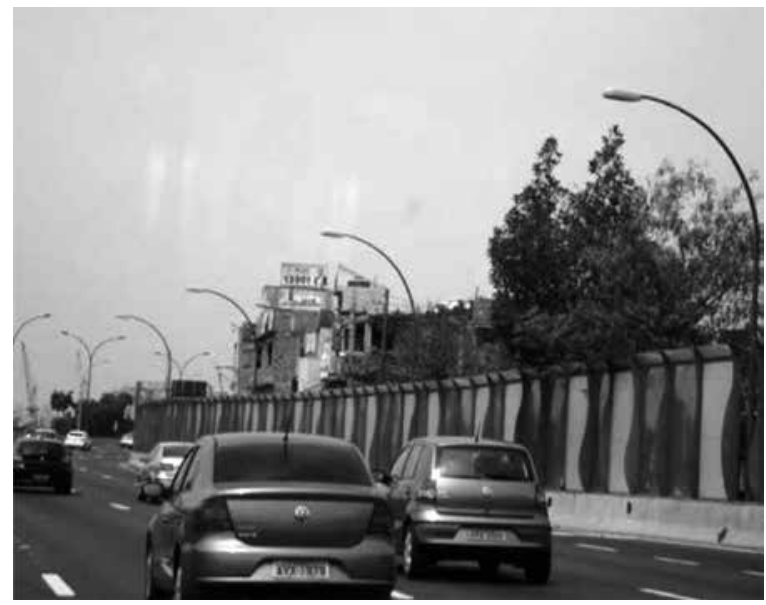

Figura 3: «Muro-(con)ducto» entre la Linha Vermelha (Línea Roja) y el complejo de favelas de Maré, en Rio de Janeiro. 
Es claro que, en un nivel más amplio, como el límite de una jurisdicción política, los muros no surgen, como podríamos imaginar, desde la aparición del Estado moderno y de la propiedad privada. De la Muralla China a los muros de las ciudades medievales, del muro de Adriano en el Imperio Romano, al Muro de Berlín durante la Guerra Fría, muchos fueron los contextos en los que las fronteras políticas adquirían esa forma de materialización. Sus funciones, por supuesto, han cambiado mucho con el tiempo. El muro de Adriano (Figura 4), por ejemplo, se servía no sólo para delimitar los dominios del Imperio Romano y asegurarle un mayor control en términos de defensa militar, sino también para controlar el flujo de personas y el comercio en relación con los pueblos que habitaban más al norte.

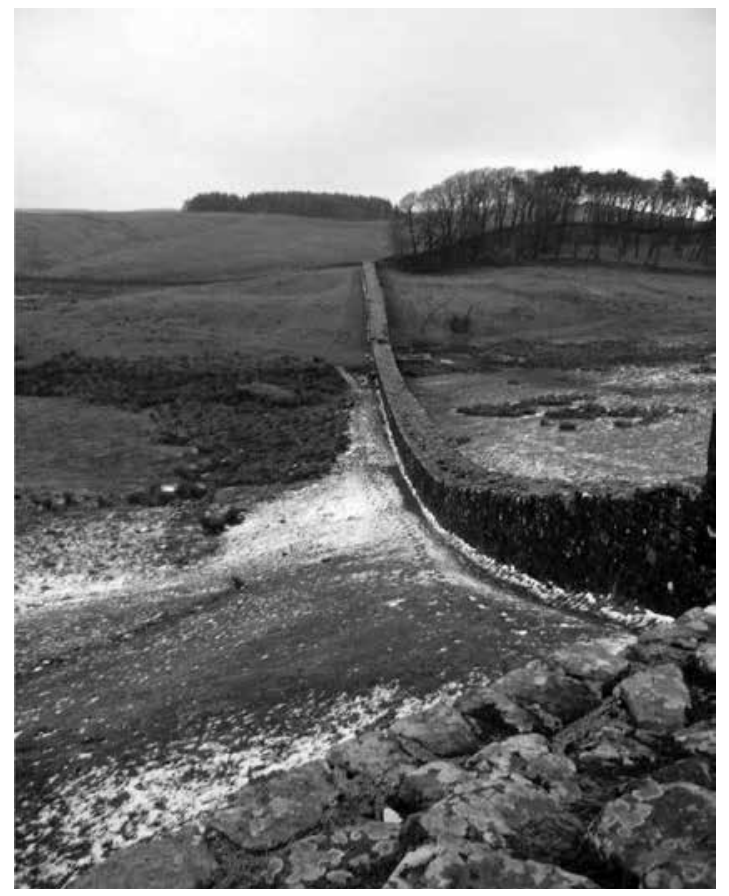

Fuente: Haesbaert, 2010.

Figura 4. Muro de Adriano, limes norte del Imperio Romano (actual Inglaterra) construido alrededor de II d. C. 
Algunos muros y cercas contemporáneos son todavía un remanentes de la época de la Guerra Fría, como el que existe entre las dos Coreas y en Guantánamo, el enclave estadounidense en territorio cubano. Ellos, sin embargo, alteran su función, y hoy se sitúan claramente dentro de un contexto marcado por el biopoder. El muro entre Corea del Norte y del Sur, vestigio de una era de la confrontación entre dos grandes bloques geopolíticos, tiene hoy la función de controlar el flujo de refugiados - y no sólo a los refugiados políticos, como durante la Guerra Fría, sino también económicos dado el creciente empobrecimiento de los norcoreanos. Guantánamo, a su vez, puede interpretarse como el prototipo de los «campos» en el marco teórico del politólogo italiano Giorgio Agamben-. Para Agamben (2002), los campos serían territorios que manifiestan la situación biopolítica de homo sacer, condición humana de la «vida desnuda» [nuda vida], situado en el limbo jurídico en el que el hombre se convierte en «matable y no sacrificable», es decir, quien mata no es posible de ser juzgado, no por las leyes humanas, ni por las divinas (no se comete pecado ni infracción a la ley).

El campo, en la conceptualización del autor, sería el territorio por excelencia del Estado de excepción, Estado en que la excepción por ser deseada, se convierte en la regla. Él se encuentra en una situación ambivalente, al mismo tiempo dentro y fuera de la ley «normal». El refugiado podría ser visto como el individuo que mejor representa esa ambivalencia legal. Para Agamben, sin embargo, el propio Estado como un todo puede adquirir la connotación de "campo» en la medida que decrete reglas de excepción en todo el territorio nacional. En un «capitalismo del desastre», como indica Naomi Klein (2008), vivimos una era de administración de las tragedias, o sea, de sucesiones de regímenes de emergencia o de excepción. Gran parte de esas situaciones de ambivalencia y marcadas por medidas autoritarias es promulgada en nombre de la «seguridad de la población» —está, por lo tanto, aceptando la renuncia a muchos derechos en nombre de su anunciada seguridad-. Para Agamben, un Estado que legisla prácticamente en nombre de la seguridad es un organismo frágil; puede defender, por ejemplo, una legislación de excepción para combatir el terrorismo y, por ende, en nombre de esa lucha, convertirse a sí mismo en «terrorista».

La difusión de las fronteras amuralladas surge en gran parte, también, en nombre del mismo discurso global de «seguridad», a través de un Estado que claramente busca reconfigurar su papel en un mundo que ya 
desde hace algunas décadas promulga su debilitamiento. Autores como Brown (2009) defienden la tesis que los muros transfronterizos son una de las formas más visibles de demostración de la fuerza de un Estado cuyo poder está en jaque y que, por eso mismo, necesita ostentar del modo más explícito posible la potencia que estaría perdiendo - especialmente en lo que refiere a su capacidad de controlar los flujos a través de sus fronteras.

El muro contemporáneo, entonces, podemos afirmar que tiene una doble e infausta función: primero, representar la fuerza de un poder - estatal- que en parte está en crisis, y segundo, como consecuencia del anterior, controlar los flujos en fronteras de un mundo cada vez más global, donde los muros físicos, materiales, han dejado de ser eficaces en las relaciones del control de la circulación más relevante a nivel internacional. ¿Cuál sería el papel de esos nuevos muros?

Más allá de su papel simbólico, tratando de evidenciar una potencia (estatal) en declive, lo máximo que un muro puede hacer es "contener» algunos flujos, de un modo espacio-temporalmente bastante limitado, en especial el flujo material y de personas, ya que los flujos inmateriales, como el propio capital, hace mucho desconocen la concreción de las fronteras y sus líneas demarcatorias. Defendemos la idea, así que, de que los nuevos muros fronterizos, en una sociedad biopolítica o de inseguridad como la nuestra, tiene una función meramente de postergar el agravamiento de una situación, de «evitar lo peor», especialmente en aquellas áreas del mundo marcadas por niveles crecientes de desterritorialización —en un sentido de aumento de las desigualdades, de la precarización y, muchas veces de la propia inestabilidad social- Por la distribución de esos muros, reveladas por la cartografía del Mapa I, podemos percibir que la gran mayoría se presenta en áreas particularmente vulnerables, con grandes problemas y/o desigualdades sociales, tanto entre países típicamente periféricos (Botswana-Zimbabue; IrakAfganistán; India-Blangadesh), cuanto entre países o regiones periféricas y semiperiféricas o centrales (Estados Unidos-México; EspañaMarruecos; Corea del Sur-Corea del Norte).

El muro, en muchos de estos casos, participa como una especie de técnica de evitación y, como tal, ejerce un efecto que proponemos llamar de efectopresa o barrera, dentro de los procesos más amplios de contención territorial. Como una represa, se busca contener el flujo (de agua) pero nunca en un sentido temporalmente definitivo o espacialmente completo, como 
los procesos clásicos de confinamiento o reclusión y su "cercamiento" por todos los lados. Se tiene la contención de un lado o hasta un cierto nivel más, con el tiempo, el flujo puede aumentar, la presión sobre la represa puede ser mayor y se es obligado a «abrir las compuertas» —un vertedero siempre está provisto y, muchas veces, es él que asegura el mantenimiento de un determinado flujo, mismo bajo control constante.

Es más o menos lo que pasa con las fronteras amuralladas, a la vez que limita el flujo de migrantes o incluso otros procesos, como el contrabando o el narcotráfico. Se sabe que el muro puede simplemente estar redireccionando el flujo, pues, nunca pasará un control total, en todas las fronteras de un país. Así, en consecuencia de la construcción de la barrera electrificada entro los enclaves españoles de Ceuta y Melilla en Marruecos, con un mayor control de las migraciones rumbo a España o, más ampliamente, a la Unión Europea, surge un aumento de la movilidad humana de África a Europa vía las Islas Canarias, por ejemplo.

A esos procesos de contención territorial por parte de grupos hegemónicos se siguen su contrapunto, eso que, inspirados en otros autores (como Telles [20I0]), proponemos denominar dinámicas de contorno, el «arte de contornear [contornamento, en portugués]", de encontrar salidas, de inventar contornos, diversas formas de evitar el control impuesto "desde arriba», en general desarrolladas como formas de resistencia por parte de grupos subalternos. Contornear, término que tiene fuerte connotación espacial, está íntimamente ligado a la idea de muro de contención, que no realiza un cercamiento total, dejando siempre la posibilidad de un desvío.

Contornear significa, al mismo tiempo, en un sentido más amplio, menos literal, «vivir en el límite», en las propias fronteras, como en la imposibilidad de superarlas, inventando un estado de liminalidad, de ambivalencia, como si pudiésemos «estar en dos lados» de la frontera al mismo tiempo —o, en otras palabras, «encima de la línea» limítrofeComo en el campo de Agamben (2002), pero aquí en un proceso con características potenciales de contra-hegemonía, esa situación ambigua no define claramento el adentro y el afuera, el legal y el ilegal, permaneciendo en una especie de limbo. Al contrario del campo, entretanto, establecido dentro de la política dominante, se trata de políticas alternativas, aunque algunas pueden ser tan o más autoritarias que las primeras - como es el caso de los narcotraficantes y de algunas las milicias en las favelas brasileras. 
En muchas favelas cariocas (ver Figura I), los muros desempeñan también, a igual que los muros fronterizos, el papel de contención: en ese caso buscando delimitar rígidamente las áreas de favelas a fin de que no se expandan en dirección de las áreas de preservación ambiental (de ahí la retórica denominada "ecolímite» para esos muros). Una de las formas de "contorneamiento" de esos procesos de contención territorial puede ser establecida, por ejemplo, por el crecimiento no más horizontal, pero vertical, con una densificación de la ocupación humana en el interior de la misma área de la favela. O bien, lo que parece ser más común, a través de la "fuga» para otras favelas, más distantes, ahora no rígidamente controladas, estrategia que es también practicada por facciones del narcotráfico en relación a las medidas de contención adoptadas por el aparato policial del Estado, con un dominio permanente de favelas bajo control anterior de esos grupos. Medidas que, en su conjunto, son de carácter paliativo, pues pueden acabar simplemente desplazando el problema en términos de su expansión e intensidad espacio-temporal en la trama de la ciudad.

Lo que sucede es que, en la imposibilidad de contar con una multiplicidad de territorios por los cuales optar, los más precariamente territorializados, lejos de componer una multiterritorialidad constantemente abierta para nuevas conexiones, nuevas territorialidades, viven en la frágil y mutable condición de «aglomerados», una situación confusa y muchas veces «ilógica» de organización territorial. Sujetos todo el tempo a la contención, destinada prioritariamente al control de sus «medios»/ espacios de circulación, como diría Foucault, viven buscando "contornear» riesgos, sea los de la extrema precarización y del hambre, sea los de la muerte violenta. Ésta es una marca mayor para aquellos que optan por los «contornos» vía circuitos ilegales de la economía, en especial del narcotráfico, y también vía la migración ilegal, como ocurre con migrantes latinoamericanos rumbo a Estado Unidos, asesinados por policías, por grandes propietarios, o simplemente por mafias de traficantes que, en verdaderos "Estados de excepción paralelos», dominan extensas áreas del territorio mexicano.

La paradoja entre un mundo cada vez más fluido y multiterritorial $\mathrm{y}$ un mundo donde nunca se construyeron tantos muros, y en tan diversas escalas, se revela por lo tanto no tan paradojal. Geometrías del poder (como diría Doreen Massey) profundamente desiguales marcan la movilidad diferencial entre los diversos sujetos contemporáneos, sean 
ellos ricos o pobres, hombres o mujeres, negros o blancos, jóvenes o viejos, participantes de esta o aquella identidad nacional o étnica. Al mismo tiempo en que, para algunos, el espacio es compuesto de arenas y conductos seguros, integrando múltiples territorios en redes de alcance planetario, para otros el espacio es una sucesión de constreńimientos -entre los cuales están los nuevos muros-. Los constreñimientos, si no están siendo constantemente remediados, por lo menos pueden ser contorneados con estrategias que no siempre representan el camino rumbo a un espacio más igualitaria y diferencialmente humano.

La sociedad de in-seguridad y el Estado biopolítico en que vivimos acaban tomando la creciente masa de desposeídos no como su producto, sino como su causa, una vez más criminalizando de forma ultrasimplificada la pobreza. En este contexto, la lucha contra la inseguridad (en su sentido más amplio), en la imposibilitad de erradicar la miseria, se puede resumir en dos medidas conexas: la banalización de la muerte de aquellos que, profundamente despreciados socialmente, pierden sus derechos más elementales, y/o su contención en especies de "campos» donde prolifera la «vida desnuda», esta condición ambivalente de limbo jurídico en el que se está, al mismo tiempo, dentro y fuera de la jurisdicción política del Estado.

Como afirmamos inicialmente, el espacio, por más restrictivo y «uniterritorial» que parezca, es también la esfera de lo múltiple, ofreciendo siempre alguna abertura para la realización de nuevas conexiones y nuevas articulaciones socioespaciales. El propio Estado contemporáneo no es marcado apenas por las medida de excepción, al servicio de la «seguridad» de grupos cada vez más (para) militarizados. Algunas iniciativas recientes, sobre todo en el espacio latinoamericano, permiten divisar nuevos horizontes todavía tímidos, probablemente, pero estimuladores de resistencias y de la lucha por otra multerritorialidad — que no sea una simple composición multifuncional al servicio de los intereses hegemónicos - que represente, efectivamente, la convivencia plural de múltiples identidades y la destrucción de los muros que, concreta o simbólicamente, demarcan la extrema desigualdad de nuestro tiempo. 


\section{Referencias bibliográficas}

Agamben, G. (2002). Homo Sacer: o poder soberano e a vida nua I. Belo Horizonte: EdUFMG.

Berman, M. (1986). Tudo o que é sólido desmancha no ar. São Paulo: Companhia das Letras.

Bourdieu, P. (1989). O Poder Simbólico. Lisboa: Difel; Rio de Janeiro: Bertrand Brasil.

Braudel, F. (1983). O Mediterrâneo e o Mundo Mediterrânico na época de Felipe II. Lisboa: Martins Fontes.

Brown, W. (2009). Murs: les murs de séparation et le déclin de la souveraineté étatique. Paris: Les Prairies Ordinaires.

Deleuze, G. y Guattari, F. (I995). Mil platôs: capitalismo e esquizofrenia. São Paulo: Editora 34.

Foucault, M. (200I). De outros espaços. En: Ditos \& Escritos. Rio de Janeiro: Forense Universitária.

- (2003). A verdade e as formas jurídicas. Rio de Janeiro: NAU Editora. (2008). Segurança, Território e População. São Paulo: Martins Fontes.

Haesbaert, R. (2004). O Mito da Desterritorialização: do "fim dos territórios» à multiterritorialidade. Rio de Janeiro: Bertrand Brasil (versión en español: El Mito de la Desterritorialización. México: Siglo XXI, 20II).

Klein, N. (2008). A doutrina do choque: a ascensão do capitalismo de desastre. Rio de Janeiro: Nova Fronteira.

Ma Mung, E. (1999). Autonomie, Migration et alterité. Dossier pour l'obtention de l'habilitation à diriger des recherches. Poitiers: Université de Poitiers.

Massey, D. (2008). Pelo Espaço: por uma nova política da espacialidade. Rio de Janeiro: Bertrand Brasil.

Souza, M. (1995). O território: sobre espaço, poder, autonomia e desenvolvimento. En: Castro, I. et al. (org.) Geografia: Conceitos e Temas. Rio de Janeiro: Bertrand Brasil.

Telles, V. (20Io). A cidade nas fronteiras do legal e do ilegal. Belo Horizonte: Argvmentvm. 